\title{
SEEING DRAWING: REPRESENTING ARCHITECTURE ON-LINE
}

\author{
ELIZABETH MUSGRAVE
}

School of Geography, Planning and Architecture

Faculty of Engineering, Physical Sciences and Architecture

University of Queensland

QLD 4072, Australia

e.musgrave@uq.edu.au

\section{ANTONY MOULIS}

School of Geography, Planning and Architecture

Faculty of Engineering, Physical Sciences and Architecture

University of Queensland

QLD 4072, Australia

a.moulis@uq.edu.au

\begin{abstract}
The capacity to engage with information held in drawings is vital to the study of architecture. For beginning architecture students to fully participate in this engagement requires the ability to relate to drawings in specific ways through a set of disciplinary conventions. These conventions are not merely about acquiring a knowledge base of architecture. They are also about techniques of reading and interpreting visual information and exercising judgements about that information. The student's means to 'find' architecture in drawing is to learn how to equate knowing with their seeing. This paper concerns the creation and implementation of a set interactive on-line tools designed to enhance learning for beginning students in architecture through the development and practise of skills for reading and interpreting architecture from drawings and images. Already at a remove from the drawing surface, the on-line environment provides a media for critical reflection on conventions of representation and their use by architects - a reflection made possible by the ability of users to manipulate parts of the drawing, dissembling and assembling knowledge in an independently controlled setting. In the making and manipulation of drawings, techniques such as adjustments of scale and reduction of detail perform vital roles in the mobilisation of knowledge. The discussion of these on-line tools and their workings provides an occasion for secondary reflection upon the conventions of architectural representation themselves and the manner in which such representations are not merely products of the discipline but a means of constituting the discipline - a surface situated as a critical juncture between the imagined and the built.
\end{abstract}

Keywords: Architectural Design and Drawing, History and Theory, On-line tools. 


\section{Introduction}

The capacity to engage with information held in drawings is vital to the study of architecture. For beginning students to fully participate in this engagement requires the ability to relate to drawings in specific ways through a set of disciplinary conventions. These conventions are not merely about acquiring the appropriate knowledge base; they are also about techniques of reading and interpreting visual information and exercising discrete judgements about that information. These skills of reading, interpreting and judging drawings for the information they offer are not easily acquired. As David Leatherbarrow notes, the development and finetuning of judgement regarding architecture conveyed through drawing comes through immersion and longer term exposure and debate (230-8). Such skills once gained are relied upon intuitively, becoming what might be called 'architectural ways of seeing'. A lack of familiarity with the relatively subtle conventions surrounding drawings and an awareness of the presence of 'convert' knowledge can lead beginning students to an anxiety about 'what they are supposed to see' when looking at a drawing that affects their confidence and their ability to fully engage in critical learning activities within the discipline.

This paper describes the creation and implementation of a set interactive learning tools designed to enhance learning for beginning students in architecture, providing the means for students to use non face-to-face time to develop and practise skills for reading and interpreting architecture from drawings and images. These tools were created to augment face-to-face tutorial teaching in the existing introductory history/theory course, Principles of Architecture, within the Architecture Program at the University of Queensland and were delivered via a course Blackboard site. Funding for developing these tools came from the Office of ViceChancellor (Academic) and the School of Geography Planning and Architecture through a successful competitive grant application to the First Year On-Line Learning Funding Scheme initiated in 2005. Funding enabled collaborative work between academics of the Architecture Program and educational instructors and designers of the Teaching and Educational Institute at the University of Queensland.

\section{Principles of Architecture Course}

The Principles of Architecture course is introductory, directing beginning students to the premise that architecture is a discipline underpinned by a set of ideas and core principles, which have formed within a broad historical frame. Presenting architecture through reference to a set of precedents that embody core principles, including key concepts of form, space, place and scale, provides a window on a range of issues within the discipline highlighted differently through history. An advantage of this approach is to provide students with terms and concepts that would assist them in demystifying an infinitely complex but immensely rich subject area.

Traditionally, beginning students of architecture acquire the skills of reading architectural drawing through the design studio setting, the context where students produce drawings of designs themselves and learn the conventions through acts of making. History and theory courses in architecture conventionally adopt a lecture and tutorial model of delivery and rely on key texts as well as visual images to convey content. The move to incorporate the acquisition of skills for reading architectural drawing in an introductory architectural history and theory course brought with it the opportunity to make more explicit those skills that are implicit in the context of the design studio. It also provides students with the ability to enhance their understanding of textual information about buildings by interrogating and correlating visual materials photographs and building plans - that are in themselves rich sources of content. It was also to understand that drawings, like texts, are open to interpretation and that the analysis of a drawing is framed by, or sets forth, a critical position. Understanding that drawings can be examined critically empowers students, providing them with a platform for forming their own judgements about buildings, qualitatively.

Most importantly, although the on-line tools were initially intended to provide a foundation for understanding the work of others, they also contribute significantly to the acquisition of skills necessary for architectural design. They do this firstly, by encouraging the development of a particular way of 'seeing' a design as it progresses. By providing a model structuring the reception of the work of others, the on-line tools also provides a mechanism that enables students to understand the role of precedent in architectural design and to utilise the lessons of precedent for their own design project work. The knowledge and skills required for learning in 
the two fields of design and history and theory within the discipline of architecture are not discrete and mastery in either is contingent upon developing architectural ways of seeing applicable to both.

\section{$3 \quad$ Reading Architectural Drawings}

Reading architectural drawings involves not just the visualisation of an abstract object, but also the interpretation of the set of spaces and spatial experiences contained therein. David Leatherbarrow writes that whilst structure and fabric are the elements of expression of architecture, space is its real concern (25). Charles Moore has stated that 'we do not draw space, but rather plans and sections in which space lurks' ("Dimensions"). Moore borrows the term 'mapping' from cartography to describe the process whereby beginning students might engage with drawn representation; 'you describe to yourself (and thereby discover) where you are and what you are near' ("Place of Houses" 207). But it is mastery of the knowledge and skills required to empathise with what is held implicitly in drawings that students must quickly acquire; a mastery that goes beyond a straightforward understanding of drawing as a tool for communicating information. Subtle yet critical meanings are revealed when a particular relationship is established between reader and representation, that is, where the reader is less a 'neutral receiver', and more 'a creative, interpretative being' (Pocock 11).

The capacity of the drawn representation to trigger perceptions or insights about space by arousing meanings in the mind of the reader has much in common with the reception of the poetic image, described by Merleau Ponty as being by 'excitement and a kind of oblique action' (8). Such action does not draw on learned knowledge alone, but knowledge that is held at a subconscious level. Simon Unwin draws on what others have described as architecture's analogous relationship to language (Forty 63) to describe the connections that beginning students must make in order to comprehend architecture:

'....architecture seems like learning a mother tongue rather than a 'second' language because in beginning to learn it the mind has no points of reference other than experience of the world itself, and an awareness of how others do it ...' ("A Bridge").

The linking of information held in a drawing to the consequences of that information for built form and space means bringing together in the imagination a knowledge of drawing conventions, disciplinary knowledge and one's own memory (or internalisation) of spaces experienced that are triggered through recognition of familiar configurations or patterns on the drawing surface. The on-line learning tools cannot directly address students' prior experience of the world but they do seek to provide a platform to practice a kind of 'oblique action' between drawings and images and in so doing understand how meaning is contained both within built form and within the modes of representing form.

\section{On-line Tools}

Each interactive on-line tool comprises a learning sequence incorporating interactive learning activities, instructional text, interactive quizzes, and a glossary of key terms. Three individual learning sequences were devised related to the following works of architecture [Kempsey Museum by Glenn Murcutt Architect, the Student Services Building at Morningside Campus TAFE by Project Services (Don Watson, Project Architect), and the Arthur and Yvonne Boyd Education Centre at Riversdale by Glenn Murcutt in association with Reg Lark and Wendy Lewin]. Resources made available through the tutorial included photographs, various architectural drawings, diagrams and text descriptions.

Particular themes are addressed in relation to each building including fundamental concepts of space and building form (Kempsey Museum), concepts of place, form and occasion (Arthur and Yvonne Boyd Education Centre) and ordering systems, abstraction and the role of historical precedent (Morningside Students Services Building). The sets of on-line tools were considered as a hierarchy of learning such that the progression between tools reflects students' developing knowledge bases. This involves the progression from simple to moderately complex buildings as well as a progression in the scope of questions based on the students' increased understanding of concepts through the semester.

Students begin their interaction by viewing a montage giving visual familiarity of the buildings and their settings, then work through drawings and diagrams that they control interactively to a series of quizzes and activities. In each instance the tutorial support activities were designed and ordered to create a learning sequence that builds upon the visual and textual descriptions of the buildings to the drawings and diagrams that provide information and the means of 
architectural analysis. Through play (the movement of the cursor over images, drawings, text and diagrams) students demonstrate to themselves how to 'see' connections between the various kinds of information that describe a built work.

By using their ability to correlate information held in plans and diagrams back to the photographic images presented in montage interactive activities enable students to orient within a work. Navigation of drawings is encouraged through a series of overlays, by which the students see buildings as comprising layers of variables - all orchestrated in response to an idea that orders elements of form and space via a series of hierarchies. Already at a remove from the drawing surface, the on-line environment provides a media for critical reflection that is made possible by the ability of the student users to manipulate parts of the drawing, dissembling and assembling knowledge in an independently controlled setting. In the making and manipulation of drawings, techniques such as adjustments of scale and reduction of detail perform vital roles in the mobilisation of knowledge. Techniques of reduction in drawings and diagrams allow for the elimination of certain details in scale drawings, to produce readings of form, space and materiality more difficult to perceive when witnessing the building in its completed state, particularly for students who are not yet trained in reading their environment in the conceptual and diagrammatic ways understood by architects. Through techniques of enhancement, drawings such as plans and sections can frame fundamental spatial dualities (eg. inside and outside) and rhythms of space and form not so clearly perceivable in photographs. Students answer quiz questions directed at demonstrating associations and assisting them to isolate and 'see' key ideas and principles at work. Immediate feedback is provided through analytical diagrams and over-drawn photographic images demonstrating relationships between principles and ideas as described in texts and lectures and their expression in built work.

The final step in the learning sequence occurs beyond the on-line environment and involves a site visit to one of the buildings [Morningside Students Services Building]. Students can test for themselves the accuracy of their reading of space and form as held in drawings and images interpreted on-line. More particularly, the student's were given to reflect upon the relationship between the drawings, diagrams and images and their own imaginations. For instance, many students expressed surprise at the scale of the built work they visited. Some had imagined the building to be bigger than they found it to be; some had imagined it to be smaller. This apparent 'failure of accuracy' between built form and its representation highlights the role of the interpretation and imagination in reading architectural representation. In each instance the misreading of scale could be traced to assumptions made about the scale of an element of building fabric measured in relation to human form as a consequence of an imagined occupation. The student's oblique action of interpretation, whereby their own work of understanding the building through drawings on-line does not entirely match the built outcome they witness, illustrates how form and space are projected as an imaginative act through drawing. The knowledge they have perceived through drawing is 'almost right' and yet a surprising 'gap' remains.

\section{$5 \quad$ Conveying Ideas and Principles}

The design of the interactive on-line learning tools is underpinned by the premise that although ideas and principles in architecture are conveyed in text and image they are overwhelmingly held in built and unbuilt works and their drawn representations. Accordingly knowledge of architecture gained from drawing relies on an understanding that ideas and principles are given presence through the ordering of structure and fabric, space and light in building; elements that constitute the language of architecture's expression (Anderson 35).

The notion that concepts cannot be separated from that which gives them presence is a difficult one, particularly when the linking of abstract knowledge to the material world hinges on a reception of drawings and images. In this instance diagrams reveal the strategic thinking that orders elements of structure and fabric and images capture the consequences of those strategies. Targeted questions prompt students to 'see' relationships by foregrounding elements of structure and form, linking them to the ordering principles and ideas that motivate them, with the added possibility that images might trigger recollections in students of previous experiences that can be cross-related. Through these moves students begin to form the disciplinary knowledge bank necessary for fully engaging with the discipline. Whatever the extent of learning gained, a vital platform is established, as students begin to realise that the means to 'find' architecture in drawing is to learn how to equate knowing with their seeing. 
Introductory texts on architecture by Francis Ching and Simon Unwin provided an important reference point for the design of these on-line learning tools. Ching's graphic presentation of strategies for ordering architecture and Unwin's presentation of architecture as constituting a language of form, both provide an opportunity for students to engage with content that might otherwise remain difficult or 'covert'. The on-line tools described here differ in that rather than being wide-ranging and generic they are particular, focused on an extended description of specific built works, enabling students to piece together a reading of building through a series of correlations. Because the tools involve analysis of built works that are accessible to students they also offer the opportunity for continuing correlations between an understanding reached on-line and subsequent experiences.

\section{Conclusion}

Finally, discussion provides an occasion to reflect on how these particular tools respond to shifts in thinking about what constitutes a context for meaningful learning. The current popularity of on-line learning tools across the education sector is a response to the recognition that students are not 'passive recipients of knowledge' but 'adventurous, independent learners' who 'learn by doing - by trial and error' (Spender). Architecture is slightly different from other fields in that learning has never been linear and sequential in character and the focus of learning has always been student-centred. In the initial thinking about how students might access the on-line learning tools it was intended that they be able to shift between exercises, choosing where they want to be and opening and closing tasks as necessary in order to 'see' connections. It is interesting to note that this intention is, to a certain extent, undermined by the nature of the Blackboard platform itself, which promotes linear learning sequences.

Nevertheless, conditions for accessing the learning tools are designed to minimise student anxiety and encourage exploration and play. Rather than the surveillance of activities typically associated with on-line tools, students are invited simply to have a go. Instead of being directly assessed online, skills mastered in order to complete the exercises are assessed indirectly, being mirrored in assignment questions. Students may take their own time to 'see' the relationships drawn out by the tools, returning as required to practice skills for reading and interpreting, reflecting the reality that student learning is uneven. Evidence from student surveys indicates students have enjoyed using the tools. Feedback from tutors suggests a greater preparedness to use aspects of an architectural language to describe work, evidence of an embedding of a metalanguage, and 'covert' knowledge, revealing representation as that critical juncture between the imagined and the built.

\section{References}

Anderson, Stanford. "Memory in Architecture." Daidalos 58 (December 1995): 23-37.

Ching, Francis. Architecture: Form Space \& Order. New York: Van Nostrand Reinhold, c1979.

Forty, Adrian. Words and Buildings: A Vocabulary of Modern Architecture. London: Thames and Hudson, 2000.

Leatherbarrow, David, Uncommon Ground: Architecture Technology and Topography. Cambridge. Mass.: The MIT Press, 2002.

Merleau-Ponty,Maurice. Trans. Colin Smith. Phenomenology of Perception, London: Routledge \& Kegan Paul, 1962.

Moore, Charles and Gerald Allen. Dimensions: Space, Shape and Scale in Architecture. New York: Architectural Record Books, c1976.

Moore, Charles, Gerald Allen and Donlyn Lyndon. The Place of Houses. New York: Holt, Rinehart and Winston, 1974.

Pocock, D. Humanistic Geography and Literature: essays of the experience of place. London: Croom Helm, Totowa N.J.: Barnes and Noble, 1981.

Spender, Dale. "Digi-kids and a new way of learning." Sydney Morning Herald: 19 May 2007.

Unwin, Simon. "A Bridge into Architecture" http://cebe.cf.ac.uk/aee/papers.html Accessed 30.01.07 12 noon.

Unwin, Simon. Unwin, Simon. Analysing Architecture. London: Routledge, 1997.

Unwin, Simon, An Architectural Notebook: Wall. London: Routledge, 2000. 